\title{
Satisfaction with democracy and collective action problems: the case of the environment*
}

\author{
Martin Halla ${ }^{\dagger}$ Friedrich G. Schneider ${ }^{\ddagger}$ and Alexander F. Wagner ${ }^{\S}$ \\ Forthcoming in Public Choice
}

Last update: August 22, 2011

(First version: July 17, 2008)

\begin{abstract}
Whether a country is able effectively to address collective action problems is a critical test of its ability to fulfill the demands of its citizens to their satisfaction. We study one particularly important collective action problem: the environment. Using a large panel dataset covering 25 years for some countries, we find that, overall, citizens of European countries are more satisfied with the way democracy works in their country if (a) more environmental policies are in place and if (b) expenditures on the environment are higher, but environmental taxes are lower. The relation between environmental policy and life satisfaction is not as pronounced. The evidence for the effect of environmental quality on both satisfaction with democracy and life satisfaction is not very clear, although we find evidence that citizens value personal mobility (in terms of having a car) highly, but view the presence of trucks as unpleasant. We also document that parents, younger citizens, and those with high levels of educational attainment tend to care more about environmental issues than do non-parents, older citizens, and those with fewer years of schooling.
\end{abstract}

JEL Classification: K32, P16, Q21, Q28.

Keywords: collective action problems, environmental economics, environmental policy, environmental quality, satisfaction with democracy.

\footnotetext{
*We would like to thank the Jubiläumsfonds of the Austrian National Bank, the University Research Priority Program Finance and Financial Markets at the University of Zurich, and the NCCR FINRISK for financial support. We thank three anonymous referees and the Editor in Chief for insightful comments that greatly improved the paper. Alberto Alesina, Mathias Dufour, Gary King, and Pippa Norris provided helpful comments on earlier versions of this paper. We also thank Elisabeth Christen, Claudia Kosovan, Silke Mader, and Jürgen Wegmayr for research assistance. The usual disclaimer applies. Data and codes to replicate the empirical analyses can be downloaded from the corresponding author's website.

${ }^{\dagger}$ Corresponding author: University of Linz and IZA; email: martin.halla@jku.at

${ }^{\ddagger}$ University of Linz, CESifo, CREMA and IZA.

${ }^{\S}$ University of Zurich and Harvard University.
} 


\section{Introduction}

In this paper we study how the resolution of an important economic problem - ensuring high environmental quality - plays a role in how citizens perceive the quality and performance of the political system in which they live in. There is a lot of public discussion about the importance of environmental issues, and it is evident that there is a greater popular awareness for environmental problems today than some decades ago (Kirchgässner \& Schneider 2003; Tanguay et al. 2004). What is less known, however, is: Just how important is the environment to individuals' perceptions of the performance of their governmental regimes, taking into account that individuals also want to achieve other, potentially conflicting goals such as economic prosperity? Answering this question is critical because most environmental policies are costly. Therefore, their ultimate acceptance will hinge on the economic value the public assigns to such policies.

Even though most individuals recognize the collective benefits of treating the environment carefully, individual considerations are likely to undermine against such actions. In economic terms, the environment is a classic case of a public good, for which a collective action problem in the sense of Olson (1965) arises: The marginal collective benefits of adopting careful actions, vis-a-vis the environment, outweigh by far the marginal private benefits (even though the latter vary across individuals). Importantly, rational individuals are aware of this wedge between what they know would be good for society, and what the optimal individual course of action is. Thus, they know that environmental quality tends to be undersupplied. Consequently, the main hypothesis that we test is that citizens want an effective resolution of this dilemma. Because solutions to collective action problems are available only through a broad consensus on policies, the success a country has in tackling collective problems like the environment is a matter, among other things, of how well a political system works. Therefore, we operationalize the research question by asking more specifically: Are citizens more satisfied with the way their political system works when more environmental policies are established and/or environmental quality is higher? And how much do they care about that issue, compared to other goals, such as personal or country-wide economic welfare?

To answer these questions, we choose as the primary dependent variable a direct measure of citizens' views on the performance of their respective governments. This measure is 'satisfaction with democracy' (SWD), a survey measure that is available for a wide range of countries. Satisfaction with the way democracy works is not an indicator of system legitimacy per se. Rather, it is one indicator of support for the performance of a democratic regime widely used in political science. Survey measures such as life satisfaction and happiness are very popular in economic research (see, among many others, Frey \& Stutzer 2000, 2002; Di Tella et al. 2003; Alesina et al. 2004; Blanchflower \& Oswald 2004; and Bjørnskov et al. 2007). Because of its comparable validity and usefulness (Linde \& Ekman 2003), SWD and related measures are also increasingly being applied (see, among others, Van Praag \& Ferrer-i-Carbonell 2004; and Wagner et al. 2009). SWD does not attempt to capture whether people support the principles of democracy, but rather how they judge it to work in practice in their actual experience. It is a summary indicator (Clarke et al. 1993) that measures satisfaction with 'the constitution in operation' (Klingemann 1999). ${ }^{1}$ As explanatory variables for SWD (besides standard individual

\footnotetext{
${ }^{1}$ Some work following Anderson \& Guillory (1997) has considered political system determinants of SWD, but
} 
and country-level economic controls) we use a broad array of environmental policy and quality variables. We compile a very large panel dataset, covering 16 countries in the time period from 1976 through 2000 (though we do not have data for every country-year combination).

We find that environmental policy and quality matter to citizens in statistically and economically important ways. Over the whole sample period, more comprehensive environmental policy is associated with more SWD. For example, an increase in the number of environmental policy measures by one standard deviation is on average associated with a rise in SWD equivalent to an increase in GDP growth by one standard deviation. Environmental expenditures also are positively associated with SWD, while environmental taxes tend to have a negative effect. For instance, by increasing environmental expenditures (measured as a share of GDP) by one percentage point, SWD for the average citizen is estimated to increase by about a quarter of a standard deviation. Our findings are robust to controlling for unobserved time-invariant heterogeneity and numerous time-varying controls at both the country level and the individual level. We also present evidence, using three distinct sample splits, that some citizens (such as parents, young citizens, and those who are highly educated) tend to care more about environmental issues than others. In sum, the results suggest that citizens, or at least important subsets of them, expect the political system to implement policies that address the environmental collective action problem.

With these findings, the paper relates to the literature on political economy, governance, and happiness. Some evidence now exists that good government (measured by broad concepts such as effectiveness, observance of the rule of law, absence of corruption, responsiveness to citizens' preferences, accountability, and political stability) is associated with greater happiness, or individual life satisfaction (Helliwell \& Huang 2008). Helliwell (2006) and Layard (2006) provide summaries of related results on the relationship between public policies and happiness. However, we do not know of any study that has considered the government's success in implementing policies addressing specific collective action problems. Perhaps closest to our study are some economics papers that have studied environmental quality (but not policy) as a determinant of happiness. One line of work has considered specific environmental amenities. For example, Van Praag \& Baarsma (2005) use the happiness approach to value airport noise. A second line of work studies broader environmental measures. Welsch (2006) presents evidence that air pollution, such as ambient nitrogen, particulates and lead, is negatively associated with subjective well-being for ten European countries (see also Welsch 2002). Welsch (2007) expands the analysis to a cross-section of 54 countries and calculates the marginal rate of substitution of income for pollution abatement. Rehdanz \& Maddison (2005) examine the relationship between climate and happiness in an empirical analysis using data on 67 countries. They find that happiness increases with a higher mean temperature in the coldest month and decreases with higher mean temperatures in the hottest month as well as that it decreases with a more months with very little precipitation of rain. ${ }^{2}$

so far no study has considered the implications of specific policy measures.

${ }^{2}$ As such, the present paper and the cited studies can also be interpreted as complementary to the existing, rich literature in economics that has addressed the economic value of specific environmental amenities. See Freeman (1985) and Environmental Protection Agency (2000) for surveys. Standard methods include, on the one hand, revealed preference methods and hedonic pricing (Viscusi 1993; Bockstael et al. 1987; Rosen 1974), including those based on recreation demand estimation (Bockstael \& McConnell 1983; Morey et al. 1993), as well as, 
All of these studies use either purely cross-sectional data, or, where they use panel data, they average happiness over all individuals in a country. However, this assumes homogenous policy effects, reduces the degrees of freedom substantially, and requires cardinality of the satisfaction scores, making it a less than ideal method for the question under study. One prior study that uses individual-level data is by Ferrer-i-Carbonell \& Gowdy (2007). However, their investigation of the relationship between individual happiness and attitudes towards ozone pollution and species extinction is limited to British data.

Our findings on environmental quality are broadly consistent with these studies. However, our results add to the existing literature in four important ways. First, this is the first study, to the best of our knowledge, to consider SWD as a measure of how much individuals care about the environment. Because environmental problems are by their nature collective problems, understanding variations in perceptions of the quality of the constitution in operation provides insights beyond those available from studying individual well-being. (We show in the robustness section that environmental policy and quality also matter for happiness.) Second, no study has evaluated the relationship between environmental policy measures and any satisfaction variable. Policies and quality may be related, but there may be important time lags, and citizens' evaluations of the effectiveness of the political system should take into account whether or not the right policies are in place. Third, we use what is, to our knowledge, the largest panel dataset of SWD to date. Fourth, we test for effects that are heterogenous across sub-groups of the population which is something papers using country-level averages cannot do.

The rest of the paper is organized as follows. Section 2 presents the hypotheses, describes the data, and discusses how our method differs from, and in our judgment improves on, approaches employed in related studies. Section 3 presents the findings. Section 4 concludes this paper.

\section{Hypotheses, data and methodology}

We begin by deriving our hypotheses. We then discuss our dependent variable(s), after which we present our key explanatory variables and our controls. Finally, we describe our estimation strategy.

\section{$2.1 \quad$ Hypotheses}

We test three simple ideas. First, economic theory suggests that collective action problems are never fully resolved. In particular, public goods such as environmental quality will generally be undersupplied, i.e., the collective marginal benefits will be greater than the collective marginal costs even when private marginal benefits and costs are already equated (Olson 1965). This results in free-riding and a tendency for environmental degradation (that is, the production of a public bad), among what Olson (1965) termed as latent groups. Most countries fall into this category. ${ }^{3}$ Citizens recognize these collective action problems. This implies that individuals

on the other hand, stated preference (contingent valuation) methods (Mitchell \& Carson 1989; Portney 1993; Hanemann 1994; Diamond \& Hausman 1994).

${ }^{3}$ In Olson's (1965) analysis, group size plays an important role, but virtually all countries are so big that individual benefits from environmental quality, net of the costs of contributing to this public good, are most likely to be negative throughout. 
would prefer better environmental quality than is usually provided. While Olson (1965) proposed some specific mechanisms for how participation can be induced in an otherwise latent group (such as through selective incentives, through repeated interaction, and as by-products of the actions of groups actually created for other purposes), we generally hypothesize that political systems that are more successful at resolving such problems of collective action will command more respect from their citizens. For this result to hold, we need only to assume that individuals regard environmental quality as a good thing. Specifically, our first hypothesis is that higher environmental quality leads to greater satisfaction with the way democracy works.

Citizens may also expect, more concretely, from the 'constitution in operation' that it allows the government to provide (at least partially) effective ways towards a resolution of the collective action problem. That is, because citizens recognize that their country is not a unitary actor and may, thus, face a collective action problem, they may perceive it as desirable to have external solutions or at least the setting of boundary conditions for individual actions imposed by the government. Some frictions in the political system are needed to generate an empirical relationship between policy and SWD. To see this, suppose that voters have single-peaked preferences over environmental policy and that environmental policy is determined by politicians to cater to the preferences of citizens (Downs 1957). In principle, in a perfectly functioning political system, under majority voting, the median voter will thus 'set' environmental policy (Black 1948). There would then exist no relation between policy and SWD (if one assumes that the SWD survey sample is representative enough to bracket the median voter): Each country, at each point in time, is effecting the policy regarded as optimal by the median voter. However, imperfections of the political system may lead to deviations from that optimum. First, elected candidates do not necessarily deliver on their campaign promises. Second, policies are not set continuously, and lobbying activities may lead to both over-provision (if environmental lobbyists are more powerful) or under-provision (if companies favoring laxer environmental standards carry the day); see Grossman \& Helpman (2001). While we do not develop a formal theoretical model in this paper, it seems plausible that on balance the political system would lead to an under-provision of policies that generate positive externalities, compared to what a full resolution of the collective action problem would require. Thus, we also test the idea that environmental policy is generally seen as an important aspect of a well-functioning democracy and will, therefore, also lead to more SWD.

In summation, our two core hypotheses are:

Hypothesis 1: More environmental policy is associated with higher SWD.

Hypothesis 2: Better environmental quality is associated with higher SWD.

Third, citizens' preferences over environmental issues may differ not only across countries but also within countries. Many environmental problems inherently are long-term challenges. A purely selfish individual might simply not care about what happens after he or she dies. Even rational economic models frequently assume, however, that individuals have a bequest motive, as they think about the welfare of their offspring. Issues of sustainable development and preserving the environment for future generations may, therefore, differentially affect individuals' perceptions of the way democracy works. If individuals expect environmental problems mainly 
to concern themselves only in the long run (or even to affect only future generations, not their own) this would suggest that (i) younger citizens and (ii) those with children should care more about environmental policy.

Hypothesis 3a: Younger citizens' SWD reacts more strongly to environmental policy and quality than the SWD of their older counterparts.

Hypothesis 3b: Parents' SWD reacts more strongly to environmental policy and quality than the SWD of non-parents.

Finally, one might argue that the awareness of such complex, long-term problems as the environment, and the awareness of what politics does to address them, might increase with educational attainment. Thus, one could expect a stronger reaction among citizens with more years of formal schooling.

Hypothesis 3c: More highly educated citizens' SWD reacts more strongly to environmental policy and quality than SWD of their lower educated counterparts.

\subsection{Data}

All our data, including the hand-collected items, will be available to other researchers upon publication of this study. Detailed information on all data used can be found in the Data appendix.

\subsubsection{Dependent variable}

The primary dependent variable for our empirical analysis is a 4-point scale measure of SWD on an individual level from the Eurobarometer survey, based on the question 'On the whole, are you very satisfied, fairly satisfied, not very satisfied or not at all satisfied with the way democracy works in our country?'. The Eurobarometer is a biannual survey launched in 1970 (turning into a quarterly survey in 2000) and includes questions about opinions and basic attitudes regarding the EU and its institutions, politics, economy and society. The question on SWD was first asked in a core of nine countries in 1973, continued to be asked of respondents from these countries in 1976, and was expanded after 1980, in a stepwise manner, to include respondents from an additional seven countries. We obtain these data from the Mannheim Eurobarometer Trend File, 1970-2002. This an integrated set of data covering harmonized variables for the years 1970 through 2002 that allow a cross-time (and cross-country) comparison. The question on SWD was not asked in every survey round in each country since 1973. However, as Table 1 shows, we have information from 313 country-years (covering responses from more than 570, 000 participants). ${ }^{4}$

As Figure 1 shows, there is substantial variation across countries in terms of the average level of SWD. Luxembourg exhibits the highest SWD in the whole EU, with a mean of 2.90.

\footnotetext{
${ }^{4}$ In our regression analysis below, we have to exclude all observations from the nine country-years from 1973 since no (comparable) information on labor market status is available. We further lose some observations due to missing information on several individual-level control variables.
} 
Norway, Denmark, the Netherlands and Austria (all values above 2.69) also do very well in terms of satisfying their citizens' expectations of democracy. Ireland, Sweden and Germany are all slightly above the EU average of 2.58 (calculated by averaging country-averages). The larger economies, such as the United Kingdom, France and Spain have values below the average. The country with the lowest levels of satisfaction is Italy, with an average of 1.96.

[Insert Table 1 and Figure 1 about here]

SWD is a survey measure and, as such, it is, in principle, subject to the same criticisms as any survey. Our line of reasoning in using this dependent variable is pragmatic: SWD has been validated and applied widely (Anderson \& Guillory 1997; Linde \& Ekman 2003), and we take its usefulness as a starting point. ${ }^{5}$ Note also that, in contrast to contingent valuation approaches, the subjects we study answered the questions about their SWD independently of a specific policy context. Thus, our approach does not require that the respondents be aware of any cause-and-effect relationship. It is not even necessary that respondents know the level of environmental quality. Therefore, our approach is cognitively less demanding than contingent valuation, and whatever relationship we find cannot be caused by strategic answers.

As an alternative dependent variable, we use overall well-being. This will allow us to contrast our findings for SWD with the related findings in this domain. The Eurobarometer includes a question on life satisfaction: 'On the whole, are you very satisfied, fairly satisfied, not very satisfied or not at all satisfied with the life you lead?, and another one on happiness 'Taking all things together, how would you say things are these days - would you say you're very happy, fairly happy, or not too happy these days?'. Since the number of available observations is substantially larger in the case of the former question (648, 083 versus 134,607$)$, we use this 4-point scale variable to capture overall well-being, and refer to this variable as life satisfaction (LS) below. Figure 1 indicates that SWD and LS are related, but by no means equivalent. The correlation between the two variables on the individual level is 0.331. On the aggregate level, we see that SWD is typically somewhat lower and more volatile than LS.

\subsubsection{Environmental policy}

We collect information from different sources in order to capture different aspects of environmental policy with different measures: (i) the existence of a wide array of certain policy measures, (ii) revenues from environmental taxes as a percentage of GDP, (iii) public expenditure on the environment as a percentage of GDP, and (iv) the share of votes for green parties.

Information on the existence of certain policy measures intended to protect the environment are collected from Binder (2002). These policy measures essentially cover the full spectrum of environmental regulation: from subsidies for renewable energy to environmental ministries, from environmental labels to the existence of a nature conservancy act. ${ }^{6}$ For each policy action, a

\footnotetext{
${ }^{5}$ See Canache et al. (2001) for a critique of SWD and Anderson (2005) for a response to that critique.

${ }^{6}$ We read this information from the tables and graphs in Binder (2002). The full list of the 16 available policy measures is as follows: quota for electricity from renewable energy sources, energy $/ \mathrm{CO}_{2}$ tax, packaging rules, sustainability council, subsidy for electricity from renewable energy sources, energy efficiency labels, environmental plan, ecolabels, environmental office, environmental expert council, general environmental act, environmental
} 
binary variable is defined that is set equal to one if a country had taken that action in a given year. For example, the variable energy $/ \mathrm{CO}_{2}$ tax is equal to one when a country had an energy tax in place in a given year and zero otherwise. We then calculate a summary measure, which is simply the number of all policy acts implemented in a given year. It encapsulates the degree to which a country has established a comprehensive set of environmental policies. It is apparent from Figure 2 that there is a tremendous variation in the adoption of such policies across the sample countries. The Netherlands started early and had implemented all 16 policy measures by 1999. In contrast, Belgium was a late adopter and still lags far behind at the end of the sample period.

\section{[Insert Figure 2 about here]}

The data on revenues from environmental taxes and government expenditure on environment protection (both measured as a percentage of GDP) are from the database of Eurostat. The evolution of the adoption of these policy measures in each country also is depicted in Figure 2. Unfortunately, these variables are not available for the whole sample period. Information on taxes is missing completely before 1980, and in the case of expenditures, even before 1990 . Notably, the level of government expenditure on environment protection is lower throughout than the revenues from environmental taxes. The revenues from environmental taxes, as a percentage of GDP, are in a range from 1.54\% (Spain 1989) to 5.39\% (Denmark 1999). Expenditures range between $0.2 \%$ (Sweden, 1995-1999) and 1.5\% (Luxembourg, 1992-1994). Of course, the ability of tax revenues (alone) to capture the degree of environmental friendliness may be limited. For instance, low revenues can either be due to little use of environmental taxes, or due to a broad and effective use of such taxes, where high tax rates have altered citizens' behavior. However, when we employ this variable below, we control for other environmental policy measures, allowing us to draw ceteris paribus conclusions.

Finally, we have data on the percentage of total cabinet posts held by green parties (weighted by days) from the Comparative Political Data Set I. This variable serves as a control variable, and we have per se no clear hypothesis on its ceteris paribus effect on SWD. We think of this variable as a good proxy for the degree of environmental awareness, and we will use it as a covariate to check the robustness of our results.

As Table 2 shows, environmental policy and environmental expenditures are (perhaps surprisingly) essentially uncorrelated. Environmental taxes are positively correlated with both the summary policy measure and environmental expenditures. As expected, we see that the larger is the share of green parties in the cabinet, the greater is the number of implemented environmental policy measures and the higher the environmental expenditures.

\section{[Insert Table 2 about here]}

reporting rules, waste disposal act, environmental protection as a constitutional goal, nature conservancy act, and a soil protection act. 


\subsubsection{Environmental quality}

To measure environmental quality we use data on (i) emissions ${ }^{7}$ and on (ii) road networks and traffic. In particular, we use data from the OECD Environmental Data Compendium 2004 on emissions of sulphur oxides $\left(\mathrm{SO}_{\mathrm{X}}\right)$, nitrogen oxides $\left(\mathrm{NO}_{\mathrm{X}}\right)$, carbon monoxide $(\mathrm{CO})$, volatile organic compounds (VOC) and carbon dioxide $\left(\mathrm{CO}_{2}\right)$. The main human sources of $\mathrm{SO}_{\mathrm{x}}$ are from burning fossil fuels, smelting and paper manufacture. $\mathrm{SO}_{\mathrm{x}}$ emissions cause adverse effects on respiratory systems of humans and animals, and damage to vegetation. In particular, they contribute to acid rain and thus have negative effects on aquatic ecosystems. $\mathrm{NO}_{\mathrm{x}}$ emissions mainly due to the burning of fossil fuels at high temperatures - play an important role in the production of photochemical oxidants and of smog, and contribute, together with $\mathrm{SO}_{\mathrm{x}}$, to acid precipitation. $\mathrm{CO}$ interferes with the absorption of oxygen by red blood cells and causes adverse health effects. Emissions of VOC are considered, along with $\mathrm{NO}_{\mathrm{x}}$, to be the main precursors of photochemical air pollution. Finally, man-made $\mathrm{CO}_{2}$ emissions result mainly from the burning of fossil fuels. The World Health Organization reports that the atmospheric concentration of $\mathrm{CO}_{2}$ has increased by more than $30 \%$ since pre-industrial times. This disturbs the balance of the earth's radiative energy budget. It is associated with a rise in the earth's surface temperature and is related to effects on climate change, sea levels and global agricultural production. $\mathrm{CO}_{2}$ contributes the largest share to global warming (OECD 2004).

Table 3 (see columns 1 to 5 ) and Figure 3 summarize the variation in emissions across countries and over time. We can see that the variation across countries (and also across categories within countries) is in fact more pronounced than the variation over time. Interestingly, many countries perform quite well in one category, but emit well above average in other categories. For instance, Norway has below average per capita emissions of $\mathrm{SO}_{\mathrm{x}}$ and $\mathrm{CO}_{2}$. It is, however, by far the biggest per capita emitter of VOC. Its 76.19 tons per 1,000 population is more than twice that of the sample average. Greece is the biggest per capita emitter of $\mathrm{SO}_{\mathrm{x}}$, but in all other categories it is below average. Luxembourg (almost an outlier) is a huge per capita emitter of $\mathrm{CO}, \mathrm{CO}_{2}, \mathrm{NO}_{\mathrm{x}}$, and VOC. Sweden, on the other hand, performs quite well in all categories.

\section{[Insert Table 3 and Figure 3 about here]}

Arguably, traffic, and in particular roadway congestion, plays a major role in day-to-day perceptions of environmental quality. To capture the quality and the extent of the road network in relation to the stock of passenger cars and all other motor vehicles (basically trucks) we construct three variables based on information collected from the OECD Environmental Data Compendium 2004. We use (i) the number of passenger cars per kilometer of the total road network and (ii) the number of trucks per kilometer of the total road network. Moreover, (iii), since the road network can be divided into 'normal' roads and highway miles, we calculate highways miles as a share of the distance spanned by a country's total road network and include this variable as a control for the structure of the road network. Columns 6 to 8 of Table 3 and

\footnotetext{
${ }^{7}$ Ideally, one would like to use the actually relevant impact for individuals. To the extent that we find emissions to be negatively associated with SWD, this effect, therefore, also captures the positive non-use value of lower emissions. Even that, however, ignores the possibility that for individuals living at the border of another country, that other country's policies and outcomes may be more relevant than the home country's policies.
} 
Figure 4 provide descriptive statistics for these three variables. There is substantial variation across countries for all three measures. Moreover, in general, we observe a (rather modest) upward trend in congestion and in the share of highways.

[Insert Figure 4 about here]

\subsection{Control variables}

\subsubsection{Country-level}

To control for various determinants of SWD other than environmental factors, we employ a set of (economic) control variables. Better economic performance is most likely associated with higher SWD. As proxies for the overall economic performance we use real GDP per capita, the real GDP growth rate, the inflation rate (the annual rate of change in the prices of consumption goods), and the annual budget deficit. Moreover, we include openness (exports plus imports divided by real GDP), the total receipts of the government as a percentage of GDP, population size, and an index of the degree of electoral fractionalization of the party-system. ${ }^{8}$

\subsubsection{Individual-level covariates}

It is common in studies of SWD to also include demographic variables. We include a set of socioeconomic control variables capturing: age, sex, family status, education, and labor market status. Clearly, we would have preferred to control for income, also on the individual level. However, this information is not available for several years and several countries. In any case, education (captured by school leaving age) and labor market status (where we compare employed citizens to unemployed, self-employed, and those out of the labor force) arguably are good proxies for income.

\subsection{Empirical strategy}

Our empirical approach is simple. We run regressions with individual SWD as the dependent variable and our key environmental variables as well as control variables (on an individual and a country level). Specifically, due to the nature of the dataset we are able to employ a panel regression, and include country and year fixed effects. Since our dependent variable SWD is measured on a four-point scale, we estimate an ordered logit model.

Two aspects of this empirical approach merit comments. First, note that to explore the effect of environmental policy and environmental quality on SWD, we have to deal with data measured on two different levels. While we observe SWD on an individual level, we measure environmental policy and environmental quality on a country-level. ${ }^{9}$ Moulton (1990) drew economists' atten-

\footnotetext{
${ }^{8}$ In particular, we use the index proposed by Rae (1968) that is defined as $1-\sum_{i=1}^{n} v_{i}^{2}$, where $v_{i}$ is the share of votes for party $i$ and $n$ the number of parties. That means, a larger value of this Rae-Index indicates a more fractionalized system. Note that, because all our countries are democracies, controlling for the extent of democracy is not likely to yield added insights. We also included the institutional quality indices found by Wagner et al. (2009) to be correlated with SWD. Whilst this substantially reduces the number of observations, the overall results remain similar and are available on request.

${ }^{9}$ In fact, we would prefer individual-level data for environmental policy and environmental quality, but these data do not exist, at least not in a dataset that measures individuals' SWD.
} 
tion to the fact that applying standard estimation methods in this setup can lead to standard errors that are biased downward. Early work tried to meet this challenge by using averaged data. But this ignores heterogeneity on the individual level and assumes homogenous policy effects. Moreover, it reduces the degrees of freedom substantially and requires cardinality of the satisfaction scores. We instead wish to make full use of the information collected at the individual level. Therefore, we follow standard practice and calculate Huber (1967)-White (1980) standard errors robust to clustering on the country-year level (Froot 1989; Williams 2000). ${ }^{10}$

The second issue we highlight is that of causality. If we observe a statistically significant coefficient on environmental policy in a regression explaining SWD, this does not necessarily mean that environmental policy causes higher SWD. To make a clean causal statement, we would need truly exogenous variation, i. e., random assignment of environmental policies across countries. In fact, however, policy is also endogenous. There are two broad classes of endogeneity concerns: reverse causation and omitted variables. It appears somewhat unlikely that there is reverse causation from SWD to environmental policy. But we cannot completely exclude the possibility that some other omitted (and perhaps unobservable) factors are correlated with both SWD and environmental policy. While this is a concern that is not to be taken lightly, we note that by including many (time-varying) control variables, we ameliorate this concern to a large extent. The longitudinal component of the dataset is also particulary useful in another way: Since we include fixed effects on a country level we control also for all unobserved time-invariant factors. Overall, this control strategy facilitates, though does not completely guarantee, a causal interpretation of our results. ${ }^{11}$

\section{$3 \quad$ Estimation results}

Our primary results for environmental policy are presented in Table 4, and those for environmental quality are presented in Table 5 . In order to provide interpretable estimation output, we report - besides the coefficients $\left(\beta_{k}\right)$ and the standard errors - standardized coefficients and changes in the predicted probabilities. Coefficients rescaled by their standard deviation (henceforth denoted by $\sigma$ ) enable a simple interpretation just like coefficients from a linear regression model. For non-binary explanatory variables we report the fully standardized coefficients, given by $\beta_{k}^{S^{f}}=\sigma_{k} \beta_{k} / \sigma_{S W D^{*}}$, which can be interpreted as the standard deviation increase in SWD associated with a one standard deviation increase in each of the respective explanatory variable, holding all other variables constant. In the case of binary explanatory variables we report the standardized coefficients, given by $\beta_{k}^{S}=\beta_{k} / \sigma_{S W D^{*}}$, which measures the estimated ceteris paribus standard deviation increase in SWD when the binary explanatory variable switches from zero to one. For the variables of primary interest we report in addition the predicted probabilities of

\footnotetext{
${ }^{10}$ Country-level regressions, where we use average SWD as the dependent variable and regress it on our environmental policy measures, all country-level control variables used in the paper, as well as country and year fixed effects, yield results that are similar overall to those produced by individual-level regressions.

${ }^{11}$ In a predecessor working paper, we employed an alternative empirical strategy, namely a hierarchical (multilevel) model. The original paper, which used only a cross-sectional dataset, is available upon request. Unfortunately, a hybrid of the two approaches (fixed effects and hierarchical modeling) is still an underdeveloped area of econometric research (Kim \& Frees 2006). While, broadly speaking, the results in the original paper were similar to the present one, the richer data and the empirical strategy employed here - in particular the ability to control for country fixed effects - imply that the present results should be seen as more reliable.
} 
being 'not at all satisfied' $(m=1)$, 'not very satisfied' $(m=2)$, 'fairly satisfied' $(m=3)$ and 'very satisfied' $(m=4)$ due to a discrete change in the respective covariate by half of a standard deviation holding all other covariates at their mean $(\overline{\mathbf{x}})$, that is, $\Delta \operatorname{Pr}(\operatorname{SWD}=m \mid \overline{\mathbf{x}}) / \Delta x_{k}$.

[Insert Table 4 about here]

\subsection{Individual and country-level characteristics}

We begin by commenting briefly on our control variables. Regarding the individual-level characteristics, it is worth noting that we find very robust effects. That is, the qualitative and quantitative results concerning the demographic covariates are rather similar across all specifications. Substantively, we find that females have a significantly lower level of SWD. Holding all other covariates constant, specification (I) in Table 4 suggests that their SWD is 0.013 standard deviations less than that of male respondents. ${ }^{12}$ With respect to age we find an inverted U-shaped relationship. Young citizens (i. e., between 15 and 24 years of age, the base group) have a comparably high SWD. Thereafter, we observe a decrease in SWD with rising age. This downward trend, however, reverses for citizens in the more senior age group (i. e., 65 years of age and older). To some extent, this suggests that SWD decreases over the period of working life (when citizens contribute most in terms of taxes). Married citizens are on average more satisfied (plus 0.053 standard deviations). The coefficients of the variables capturing individual economic status by and and large are mainly statistically significant. As expected, unemployed citizens are - compared to employed citizens - less satisfied (minus 0.280 standard deviations). Somewhat surprisingly, self-employed individuals are also comparably less satisfied with the way democracy works (minus 0.022 standard deviations). It is, for instance, possible that entrepreneurial citizens would on average value more opportunities for political involvement, or entrepreneurial activity per se typically reveals certain shortcomings of the political system. Citizens out of the labor force (i. e., the retired or housewives) do not exhibit a statistically significant different level of SWD compared to employed citizens. Finally, satisfaction rises with education. Compared to the base group of citizens with low educational attainment (i. e., below 16 years of formal education), the SWD of citizens with medium and high levels of educational attainment is greater by 0.034 and 0.086 standard deviations, respectively. The peak level of SWD, however, is achieved by currently enrolled citizens; their SWD is even 0.128 standard deviations larger.

The results for the country-level characteristics are also instructive (see, for instance specification (II) in Table 4). Richer, faster-growing, smaller economies and those that run larger deficits but have lower government revenue to GDP ratios have higher SWD. Openness and SWD are negatively correlated. Inflation enters positively, which may have to do with the fact that in the period under consideration, inflation in these countries was relatively moderate and arguably related to economic growth.

\footnotetext{
${ }^{12}$ It is outside the scope of this paper to determine whether or not this may be explained by discrimination against women in various aspects of live, such as the labor market, but this would appear to be an important question for further research.
} 


\subsection{Environmental policy}

The primary finding of interest in Table 4 is the impact of our summary measure of environmental policy on SWD. The strong and robust result that emerges is that, controlling for a large variety of individual and country-level explanatory variables, a more developed environmental policy is applauded by citizens. The summary measure enters as a statistically significant determinant of SWD. Specification (II) suggest that an increase in the number of implemented policy measures by one standard deviation (which is equal to 3.78 policies) increases SWD by 0.09 standard deviations (which is equal to 0.075 points). Equivalently, the probability that a citizen is 'fairly satisfied' ('very satisfied') with the way democracy works is 2.9 (1.3) percentage points higher if the number of implemented policy measures increases by half of a standard deviation. This quantitative effect is comparable to that of real GDP growth. The average marginal effect (not tabulated) of these two variables is about the same: An additional environmental policy measure implemented, or an increase in GDP growth by one percentage point both increase SWD by 0.006 points. Compared to the gender-gap in SWD, an additional environmental policy measure creates an average effect seven times larger than the male-female difference in SWD.

Notably, the results on the effect of our summary measure of environmental policy on SWD remain unchanged when controlling for the share of green parties in the cabinet, as in specification (III) of Table 4. This is important because the green parties' percentages of total cabinet posts can be interpreted as time-varying proxies for the degree of environmental awareness. Specification (IV) finally introduces fiscal activities of the government with respect to environmental policies; note here that the sample size is reduced considerably. Still, even when we control for environmental taxes and expenditures in this smaller sample, the effect of the summary measure of environmental policy is present and significant ( $p$-value of 0.09). We also tested whether the effect of the summary measure changes over time (i. e., we introduced interaction terms between year fixed effects and the summary measure). While we find that the effect is significantly different in various years, no clear long-run trend is visible. These results are available upon request. ${ }^{13}$

In line with the estimated positive effect of our summary measure of environmental policy on SWD, we find that citizens' SWD increases with public expenditures on the environment. An increase in expenditures by one standard deviation ( 0.272 percentage points of GDP) is associated with a 0.062 standard deviation increase in SWD. The estimated average marginal effect (i. e., the effect of an increase in expenditures by one percentage point of GDP) is equal to 0.055 points. With respect to environmental taxes we find a negative effect on SWD. One could have expected that environmental taxes might have a positive effect on SWD due to the potential double dividend they offer in the form of a reduction of negative externalities and a reduction of other distortionary taxes. However, our results do not support this prediction. Instead, citizens seem to find only government intervention through enhanced spending appropriate, but SWD

\footnotetext{
${ }^{13}$ In untabulated regressions, we have considered 'kitchen-sink' models including binary variables for all of the individual policy measures. Only a few individual policy measures are consistently positively or negatively related with SWD; instead, the sign (and significance) often depends on the introduction of additional controls. The statistical significance of individual measures may also arise as an artefact of the correlations between the many policy variables included in the horserace. While the summary measure is, by definition, a cruder proxy for environmental policy, the results obtained with it are more stable.
} 
is ceteris paribus lower when environmental taxes are higher. Our estimation suggests that an increase in environmental taxes by one standard deviation decreases SWD by 0.073 standard deviations. The average marginal effect is 0.025 points. The positive effects of the summary measure and the public environmental spending, in combination with the negative effect of taxes, are consistent with an economic understanding of environmental problems as collective action problems, i. e., the notion that most individuals care about the environment but few are willing to bear the costs of protecting it. Overall, we interpret our findings as substantial support for Hypothesis 1 that the adoption of more policy measures increases SWD.

\subsection{Environmental quality}

The second hypothesis that we test is that environmental quality should be positively associated with SWD. Table 5 shows the results for this hypothesis, first introducing various categories of emissions, then introducing three measures of traffic and congestion, and then including all measures (along with the share of green parties in the cabinet). A number of interesting findings emerge from studying these sets of variables both individually and jointly.

Across all specifications we find negative coefficients for sulphur oxide $\left(\mathrm{SO}_{\mathrm{X}}\right)$, nitrogen oxide $\left(\mathrm{NO}_{\mathrm{x}}\right)$, and carbon monoxide emissions $(\mathrm{CO})$. However, only the estimated effects of nitrogen oxides are statistically significant throughout. An increase in emissions of nitrogen oxides by one standard deviation decreases SWD by about 0.1 to 0.15 standard deviations. The estimated positive effect of emissions of volatile organic compounds $(V O C)$ and carbon dioxide $\left(\mathrm{CO}_{2}\right)$ are puzzling. It seems that these categories of emissions are correlated in specification (I) with unobserved time-varying SWD-enhancing mobility factors. After controlling for traffic and congestion in specifications (III) and (IV), the statistical significance of carbon dioxide vanishes.

With respect to our measures of traffic and congestions we find a positive effect for the carroad ratio, and a robust negative effect for the truck-road ratio. It seems that citizens value their personal mobility (in terms of having a car) quite highly, and even accept a large car-road ratio (i. e., a higher likelihood of congestion). By contrast, they perceive heavy truck traffic to be unpleasant and they favor governmental regulations to reduce it. Especially the latter result is plausible, given the significant amount of public discussion of this topic in some countries. (See, for example, the transit traffic conflict between the Austrian government and the EU).

In summary, the results on environmental quality are not as strong as those on environmental policy and provide only weak evidence in favor of Hypothesis 2. Citizens may be less informed about environmental quality (captured, for example, by emissions) and/or may hold the domestic political system less responsible for environmental protection within this domain, since they perceive it as a more global phenomenon where national action is less effective.

[Insert Table 5 about here]

\subsection{Life satisfaction}

Our equivalent analysis of the effect of environmental policy on LS is summarized in the upper panel of Table 6, while the results for environmental quality are summarized in the lower panel. 
For environmental quality, we obtain, overall, the same patterns as for SWD. As for policy, we can see that the summary measure of environmental policy also has a statistically significant positive effect on LS. However, this effect is somewhat smaller and less robust than found previously. In specifications (I) through (III) the estimated effect is highly statistically significant, and suggests that an increase of the summary measure by one standard deviation increases LS by up to 0.079 standard deviations. In specification (IV), where we include environmental taxes and expenditures as additional covariates, however, statistical significance vanishes and the estimated effect is basically zero. Likewise, we find a smaller (and less significant) effect of public environmental expenditures on LS. The average marginal effect is about 0.025. Environmental taxes turn out not to be a significant determinant of LS. Overall, we interpret these results as evidence that SWD and LS are related but distinct concepts. In our context we find a stronger relationship between SWD and (environmental) policy measures. This finding seems plausible since SWD refers to the current political situation, while LS is an all-encompassing evaluation of individuals' current life conditions.

[Insert Table 6 about here]

\subsection{Heterogenous effects}

To operationalize causal heterogeneity with respect to the impact of environmental measures on SWD, and to test Hypotheses $3 a, 3 b$ and $3 c$, we split the sample along the dimensions of age, parenthood, and educational attainment.

With respect to age, we distinguish between young (below 34 years of age) and old (at least 55 years of age) citizens. Unfortunately, the Eurobarometer does not include a specific question on parenthood. However, respondents are asked (in 90 usable country-years) 'How many children under 15 are there living at home?'. ${ }^{14}$ Given that, in almost all cases, mothers obtain (physical) custody after divorce (or separation) this question can be used to construct valid information on parenthood for women. Therefore, when we refer to parents we distinguish between female parents and female non-parents. To explore the effect among poorly and highly educated citizens we compare estimations based on a sample of citizens with 15 years of formal education or less, and citizens with at least 16 years of formal education. ${ }^{15}$ Since we cannot control for income in our full sample, educational attainment incorporates not only the effect of education but (potentially) also the effect of income.

Table 7 provides the results. Consider first the upper panel, where the first two columns show the effects of environmental measures on SWD for young and old citizens. A comparison of the standardized estimates (and their significance) indicates that younger citizens care comparably more about environmental policy. For instance, an increase in the summary measure by one standard deviation, increases the SWD of young citizens by 0.070 standard deviations, and those of older citizens by only 0.056 standard deviations. The next two columns differentiate between

\footnotetext{
${ }^{14}$ To be precise, in a subset of waves the survey differentiates further between younger (below 8 years of age) and older (above 8 and below 15 years of age) children.

${ }^{15}$ The data allow us to consistently distinguish between citizens who are still studying (8.9\%), those who have up to 15 years (29.04\%), between 16 and 19 years $(37.68 \%)$ and 20 or more years $(24.37 \%)$ of formal education.
} 
parents and non-parents. While the estimated effect of our summary measure of environmental policy is not statistically significant (at conventional levels) in either sample, it is remarkable that the estimated coefficient is three times larger for parents and has a smaller standard error. With respect to environmental expenditures we find that in the case of parents each standard deviation increase in these expenditures increases SWD by 0.105 standard deviations. This effect is highly statistically significant. The equivalent effect for non-parents is only 0.066 standard deviations. Comparing poorly and highly educated citizens, we find a comparatively stronger effect of the summary measure in the latter sample (0.092 versus 0.029). ${ }^{16}$ We find similar patterns in an equivalent analysis of LS (not shown).

Overall, we interpret these findings on heterogenous effects as broadly, though not extremely strongly, supportive for Hypotheses $3 a$ through $3 c$ as far as environmental policy is concerned. By contrast, our analysis of heterogenous effects of environmental quality on SWD (and LS) does not yield important differences between the sub-groups of citizens under consideration.

[Insert Table 7 about here]

\section{Conclusions}

This paper investigates satisfaction with democracy in the presence of an especially important and topical collective action problem, the environment. Our first set of new results shows that, overall, a focus on environmental policy is associated with greater SWD in statistically and economically important ways in our sample of 16 European countries across a period of up to 25 years. Larger public expenditures on the environment tend to increase an average citizen's satisfaction score, while environmental taxes ceteris paribus reduce it. The findings for environmental quality are more ambivalent. Broadly speaking, parents, young citizens and those with high levels of educational attainment worry significantly more about appropriate environmental policy than do non-parents, older citizens, and those with fewer years of schooling. These results are intuitive and should be of interest to scholars (including those studying collective action problems other than those problems related to the environment) and policy-makers alike.

Although our paper thus makes progress on the important question of how the environment matters for citizens' SWD, it also has its limitations. Perhaps the primary drawback is that we are not offering a theoretical framework that neatly pins down exactly which variables should play a role in SWD and which should not. This issue is partly addressed by our panel data setup that allows us to control for unobserved time-invariant heterogeneity. But even that approach does not completely exclude the possibility that time-varying omitted variables are driving some of our results. Further theoretical and conceptual work on SWD can, therefore, be fruitfully conducted.

\footnotetext{
${ }^{16}$ If we redefine the group of highly educated citizens to comprise those with 20 or more years of formal education (instead of 16 or more years), the effect of the summary measure increases to 0.131 .
} 


\section{References}

Alesina A., Di Tella R., \& MacCulloch R. (2004). Inequality and happiness: are Europeans and Americans different? Journal of Public Economics, 88, 2009-2042.

Anderson C. Good questions, dubious inferences, and bad solutions. Unpublished manuscript, University of Wisconsin-Madison (2005).

Anderson C. J. \& Guillory C. A. (1997). Political institutions and satisfaction with democracy: a cross-national analysis of consensus and majoritarian systems. American Political Science Review, 91, 66-81.

Binder M. (2002). Umweltpolitische Basisinnovationen im Industrieländervergleich. Berlin: Freie Universität Berlin Forschungsstelle für Umweltpolitik.

Bjørnskov C., Dreher A., \& Fischer J. (2007). The bigger the better? Evidence of the effect of government size on life satisfaction around the world. Public Choice, 130, 267-292.

Black D. (1948). On the rationale of group decision-making. Journal of Political Economy, 56, $23-34$.

Blanchflower D. G. \& Oswald A. J. (2004). Well-being over time in Britain and the USA. Journal of Public Economics, 88, 1359-1386.

Bockstael N. E., Hanemann M. W., \& Kling C. L. (1987). Estimating the value of water quality improvements in a recreational demand framework. Water Resources Research, 23, 951-960.

Bockstael N. E. \& McConnell K. E. (1983). Welfare measurement in the household production framework. American Economic Review, 73, 806-814.

Canache D., Mondak J. J., \& Seligson M. A. (2001). Meaning and measurement in cross-national research on satisfaction with democracy. Public Opinion Quarterly, 65, 506-528.

Clarke H. D., Dutt N., \& Kornberg A. (1993). The political economy of attitudes toward polity and society in Western European democracies. Journal of Politics, 55, 998-1021.

Di Tella R., MacCulloch R. J., \& Oswald A. J. (2003). The macroeconomics of happiness. Review of Economics and Statistics, 85, 809-827.

Diamond P. A. \& Hausman J. A. (1994). Contingent valuation: is some number better than no number? Journal of Economic Perspectives, 8, 45-64.

Downs A. (1957). An economic theory of democracy. New York: Harper.

Environmental Protection Agency (2000). Guidelines for preparing economic analysis. Washington, D.C.: Environmental Protection Agency.

Ferrer-i-Carbonell A. \& Gowdy J. M. (2007). Environmental degradation and happiness. Ecological Economics, 60, (pp. 509-516). 
Freeman M. A. (1985). Methods for assessing the benefits of environmental programs. In A. V. Kneese \& J. L. Sweeney (Ed.), Handbook of Natural Resources and Energy Economics, (pp. 223-270), Amsterdam: North Holland.

Frey B. S. \& Stutzer A. (2000). Happiness, economy, and institutions. Economic Journal, 110, 918-138.

Frey B. S. \& Stutzer A. (2002). What can economists learn from happiness research? Journal of Economic Literature, 40, 402-435.

Froot K. A. (1989). Consistent covariance matrix estimation with cross-sectional dependence and heteroskedasticity in financial data. Journal of Financial and Quantitative Analysis, 24, $333-355$.

Grossman G. M. \& Helpman E. (2001). Special interest politics. Cambridge: MIT Press.

Hanemann M. W. (1994). Valuing the environment through contingent valuation. Journal of Economic Perspectives, 88, 19-43.

Helliwell J. F. (2006). Well-being, social capital and public policy: what's new? Economic Journal, 116, C34-C45.

Helliwell J. F. \& Huang H. (2008). How's your government? International evidence linking good government and well-being. British Journal of Political Science, 38, 595-619.

Huber P. J. (1967). The behavior of maximum likelihood estimates under nonstandard conditions. Proceedings of the Fifth Berkeley Symposium on Mathematical Statistics and Probability, $1,221-223$.

Kim J. \& Frees E. W. (2006). Omitted variables in multilevel models. Psychometrika, 71, 659-690.

Kirchgässner G. \& Schneider F. (2003). On the political economy of environmental policy. Public Choice, 115, 369-396.

Klingemann H.-D. (1999). Mapping political support in the 1990s: a global analysis. In P. Norris (Ed.), Critical citizens: global support for democratic governance, (pp. 31-57), New York: Oxford University Press.

Layard R. (2006). Happiness and public policy: a challenge to the profession? Economic Journal, 116, C24-C33.

Linde J. \& Ekman J. (2003). Satisfaction with democracy: A note on a frequently used indicator in comparative politics. European Journal of Political Research, 42, 391-398.

Mitchell R. C. \& Carson R. T. (1989). Using surveys to value public goods: the contingent valuation method. Washington, D.C.: Resources For the Future.

Morey E. R., Rowe R. D., \& Watson M. (1993). A repeated nested-logit model of atlantic salmon fishing. American Journal of Agricultural Economics, 75, 578-592. 
Moulton B. R. (1990). An illustration of a pitfall in estimating the effects of aggregate variables on micro units. Review of Economics and Statistics, 72, 334-338.

OECD (2004). OECD environmental data compendium 2004. Paris: OECD.

Olson M. (1965). The logic of collective action: public goods and the theory of groups. Cambridge: Harvard University Press.

Portney P. R. (1993). The contingent valuation debate: why economists should care. Journal of Economic Perspectives, 8, 3-17.

Rae D. (1968). A note on the fractionalization of some european party systems. Comparative Political Studies, 1, 413-418.

Rehdanz K. \& Maddison D. J. (2005). Climate and happiness. Ecological Economics, 52, 111125.

Rosen S. (1974). Hedonic prices and implicit markets. Journal of Political Economy, 82, 34-55.

Tanguay G. A., Lanoie P., \& Moreau J. (2004). Environmental policy, public interest and political market. Public Choice, 120, 1-27.

Van Praag B. M. \& Baarsma B. E. (2005). Using happiness surveys to value intangibles: the case of airport noise. Economic Journal, 115, 224-246.

Van Praag B. M. \& Ferrer-i-Carbonell A. (2004). Political satisfaction. In B. M. Van Praag \& A. Ferrer-i-Carbonell (Ed.), Happiness quantified, (pp. 96-113), Oxford University Press.

Viscusi K. (1993). The value of risks to life and health. Journal of Economic Literature, 31, $1912-1946$.

Wagner A. F., Schneider F. G., \& Halla M. (2009). The quality of institutions and satisfaction with democracy in Western Europe - a panel anlysis. European Journal of Political Economy, $25,30-41$.

Welsch H. (2002). Preferences over prosperity and pollution: environmental valuation based on happiness surveys. Kyklos, 55, 473-495.

Welsch H. (2006). Environment and happiness: valuation of air pollution using llife satisfaction data. Ecological Economics, 58, 801-813.

Welsch H. (2007). Environmental welfare analysis: a life satisfaction approach. Ecological Economics, 62, 544-551.

White H. (1980). A heteroskedasticity-consistent covariance matrix estimator and a direct test for heteroskedasticity. Econometrica, 48, 817-830.

Williams R. L. (2000). A note on robust variance estimation for cluster-correlated data. Biometrics, 56, 645-646. 


\section{Data appendix}

The information on the individual-level variables satisfaction with democracy, life satisfaction, age, sex, family status, education, labor market status, and children is from the Mannheim Eurobarometer Trend File, 1970-2002. This dataset is prepared by the Zentralarchiv fur Empirische Sozialforschung (Hermann Schmitt and Evi Scholz) and, for instance, available as ICPSR Study No. 435\%. We start with all observations for which a measure of satisfaction with democracy is available (see Table 1). In our estimation analysis, however, we cannot exploit the full set of observations, since information on some covariates is missing. Information on age enters into the estimations based on binary variables for six age-groups (15 to 24,25 to 34,35 to 44,45 to 54 , 55 to 64 , and over 65 years) where the youngest group serves as the base group. Family status is captured by a binary variable equal to one if the respondent is married, and zero otherwise. Educational attainment is incorporated based on binary variables capturing if a respondent is still enrolled in school, has below 15 years of formal education (base group), between 16 and 19 years, or more than 20 years. With respect to labor market status we distinguish between respondents who are employed (base group), self-employed, unemployed and out of the labor force.

The information on the country-level covariates is from different sources. First, information on real GDP per capita (in constant prices), the real GDP growth rate (percentage change from previous year), the inflation rate (measured as the annual percentage increase in the prices of consumption goods), openness (exports plus imports divided by real GDP per capita; all measured in constant prices), and population size (in thousands) is from the Penn World Tables (version 7.0). Further information is provided by http://pwt.econ.upenn.edu/. Second, the information on tax receipts (total tax receipts of government as a percentage of GDP), the annual budget deficit (government primary balance) as a percentage of GDP, and the index of electoral fractionalization of the party-system (following Rae 1968), green parties' percentages of total cabinet posts (weighted by days) are from the Comparative Political Data Set I, 1960-2008 provided by Klaus Armingeon, Sarah Engler, Panajotis Potolidis, Marléne Gerber and Philipp Leimgruber; see http://www .ipw . unibe.ch/content/team/klaus_armingeon/ comparative_political_data_sets/index_ger.html.

Our measures of environmental policy are from two different sources. First, information on the existence of a quota for electricity from renewable energy sources, an energy $/ \mathrm{CO}_{2}$ tax, a packaging rules, a sustainability council, a subsidy for electricity from renewable energy sources, energy efficiency labels, an environmental plan, ecolabels, an environmental office, an environmental expert council, a general environmental act, environmental reporting rules, a waste disposal act, environmental protection as a constitutional goal, a nature conservancy act, and a soil protection act is collected from Binder (2002). We obtained the information by reading them from the graphs. The graphs are fortunately of the quality that they allow the unambiguous identification of all cases. Second, data on revenues from environmental taxes and government expenditure on environment protection (both measured as percentages of GDP) are from the database of Eurostat. (Data were retrieved on 2011/04/18.)

Our measures of environmental quality are from two primary sources. Firstly, information on emissions of $\mathrm{SO}_{\mathrm{x}}, \mathrm{NO}_{\mathrm{x}}, \mathrm{CO}, \mathrm{VOC}$ and $\mathrm{CO}_{2}$ from energy use is collected from the $O E C D$ 
Environmental Data, Compendium 2004. Secondly, the information on the road network (total length of road networks, length of highways) and on the stock of road vehicles (total number of passenger cars in use, total number of other motor vehicles in use) is obtained from the OECD Environmental Data, Compendium 2006/200\%. 


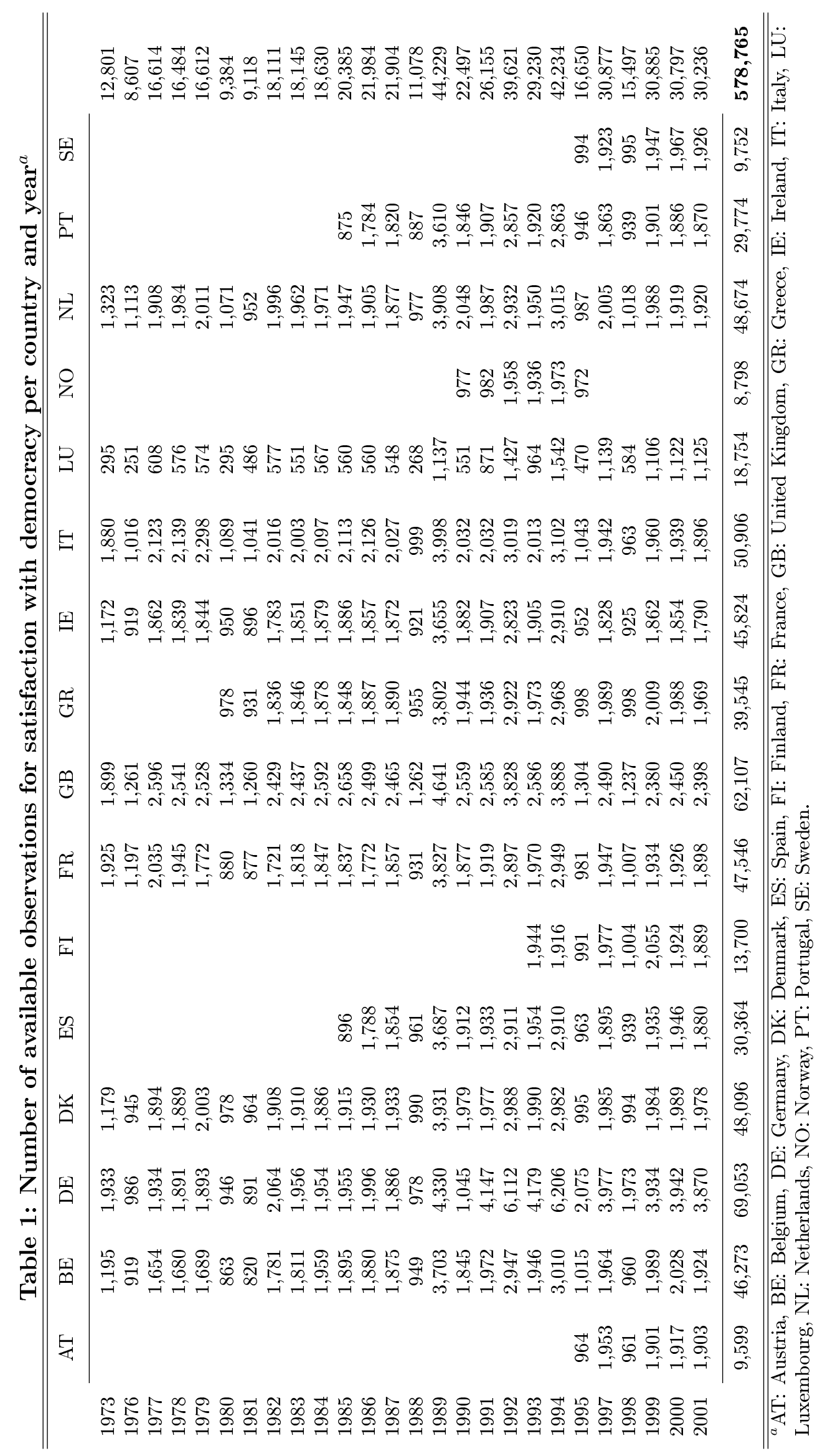




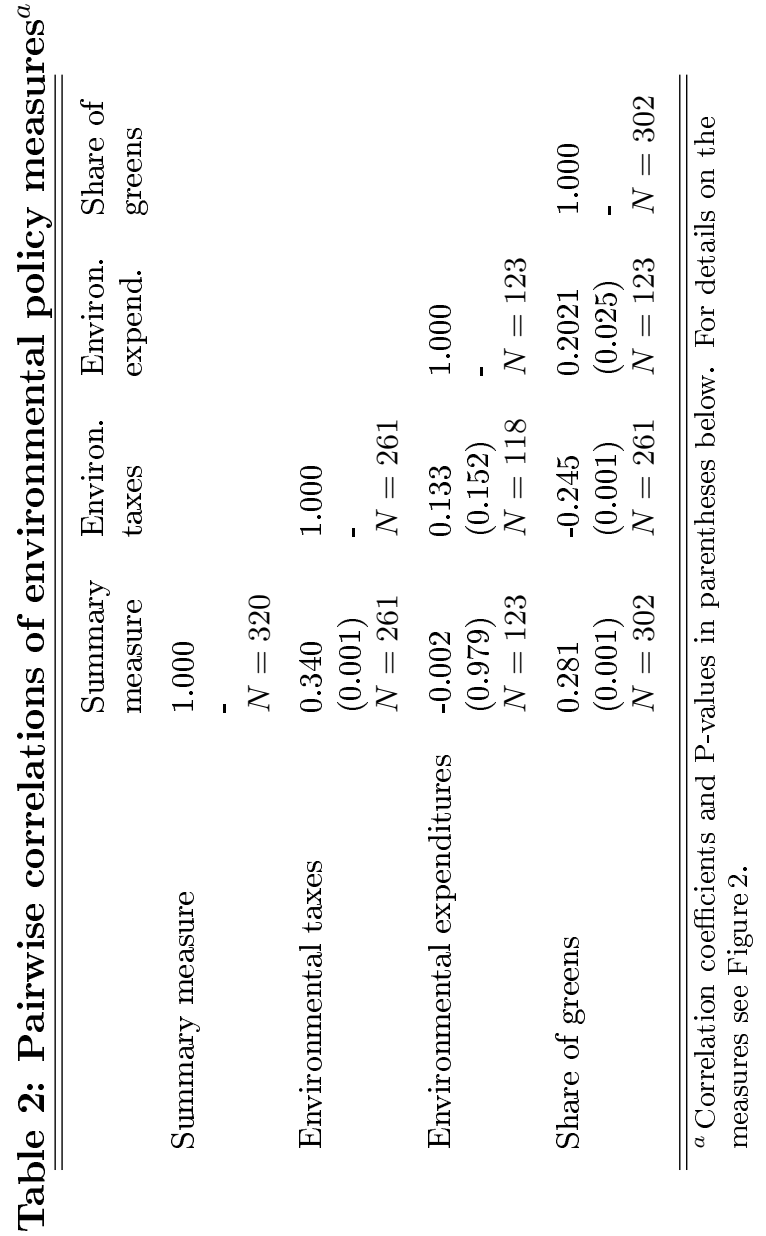




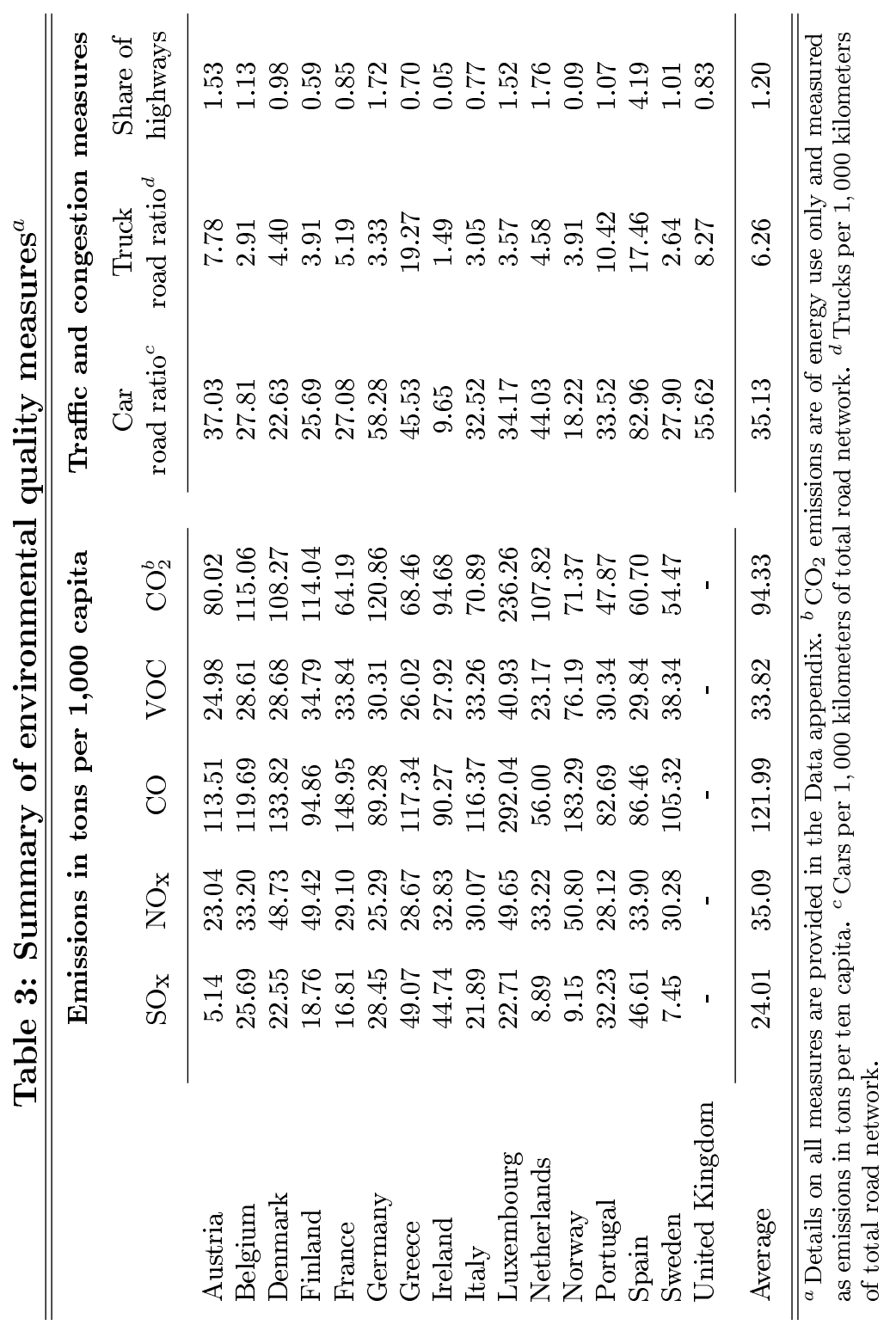




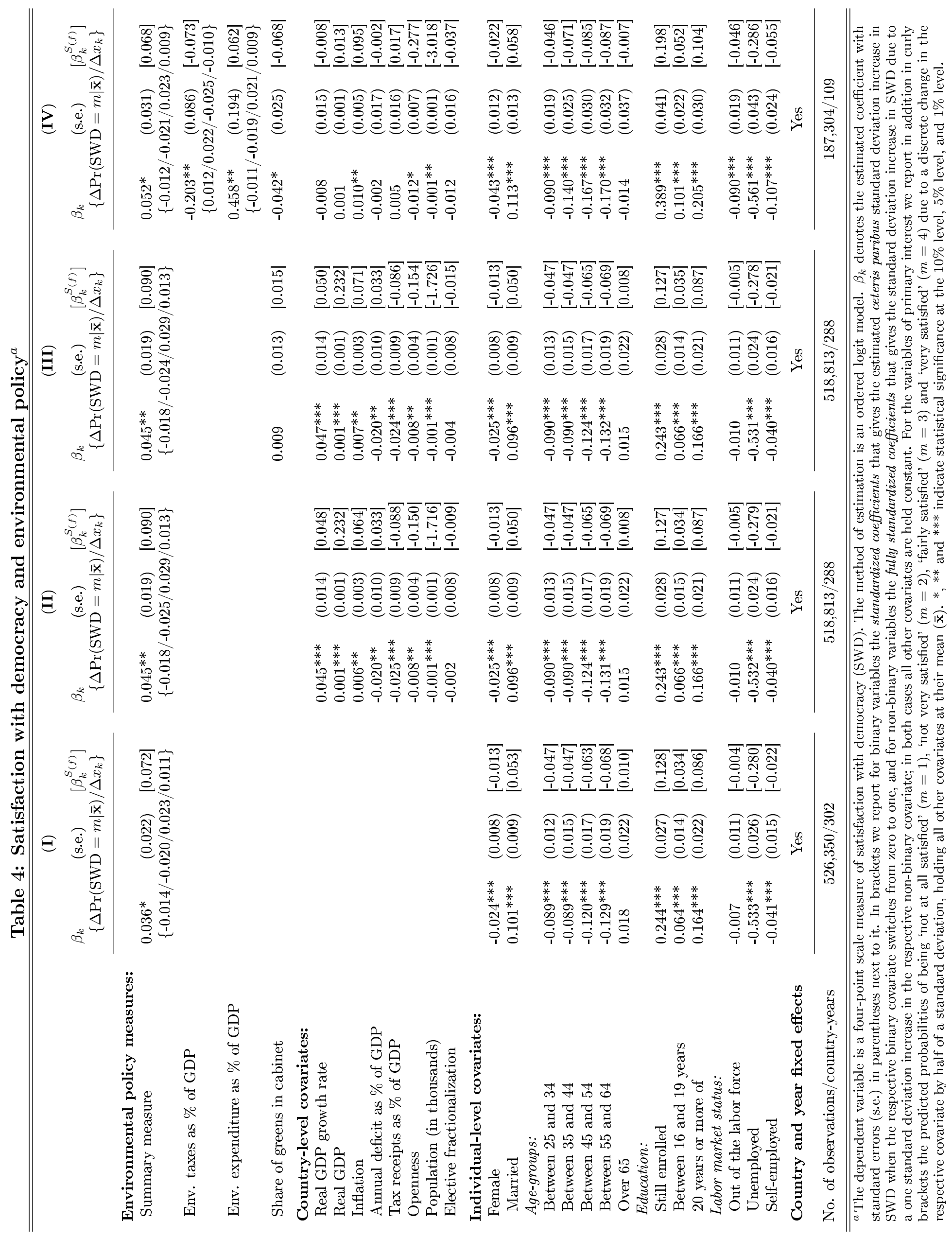




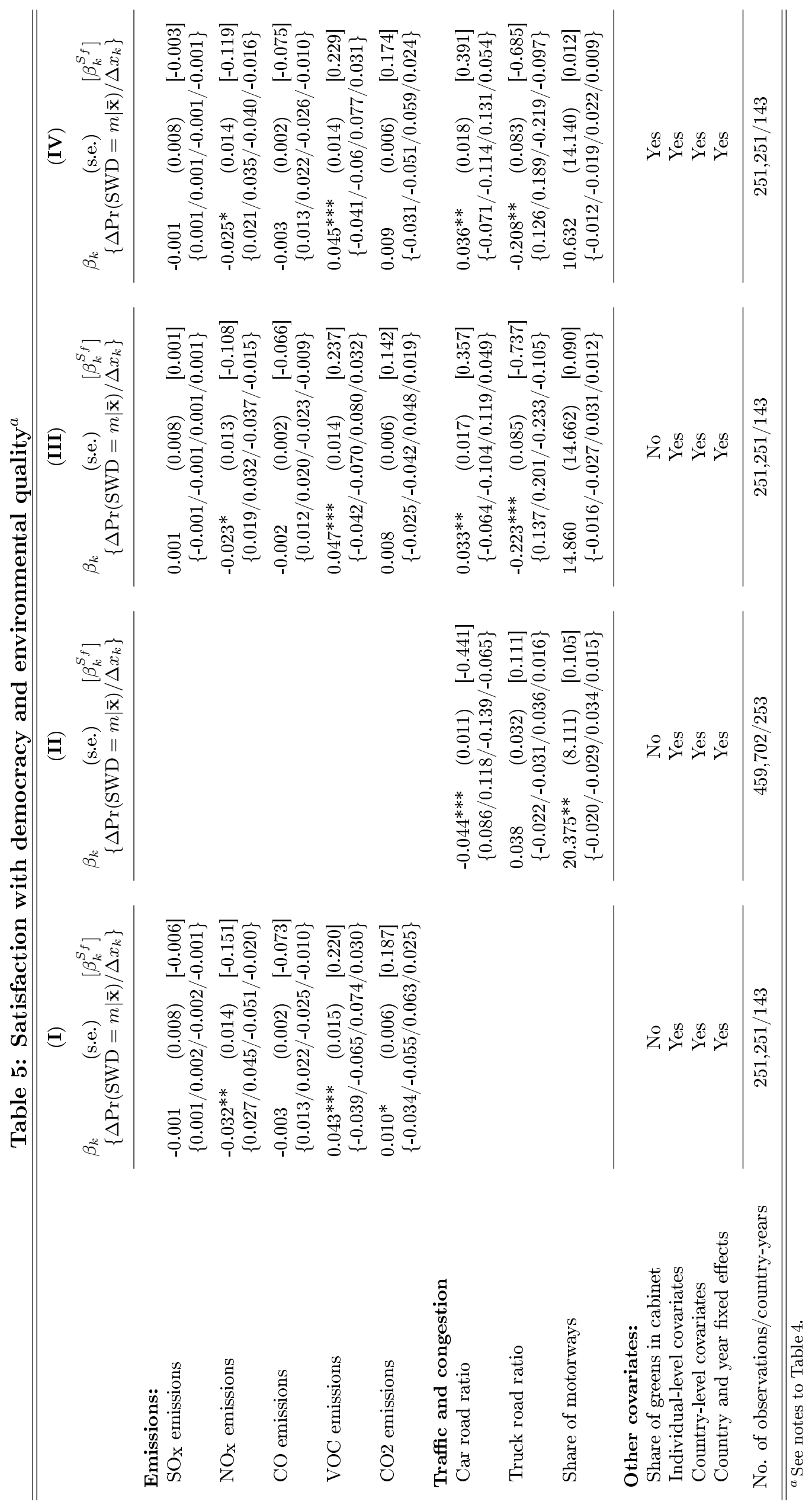




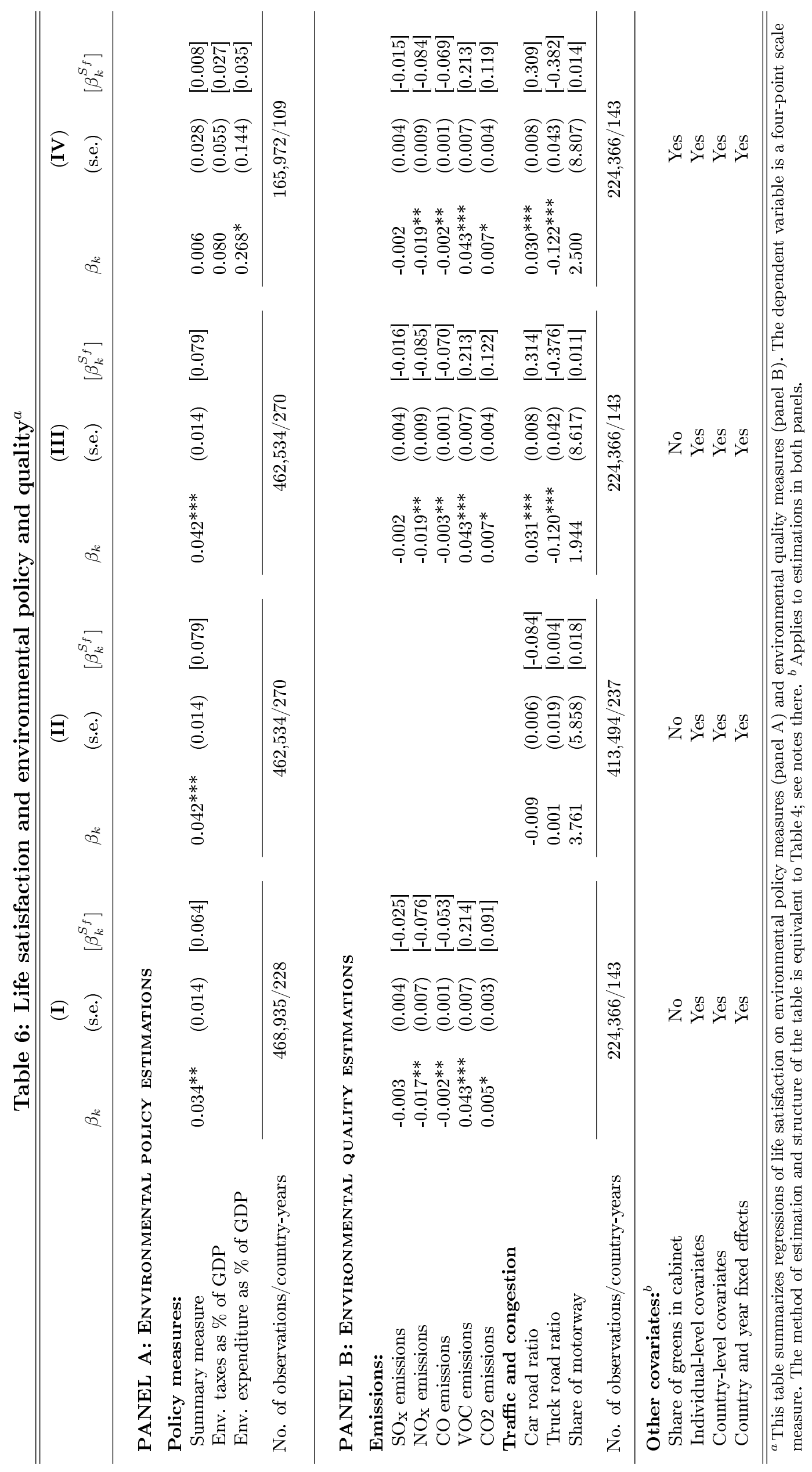




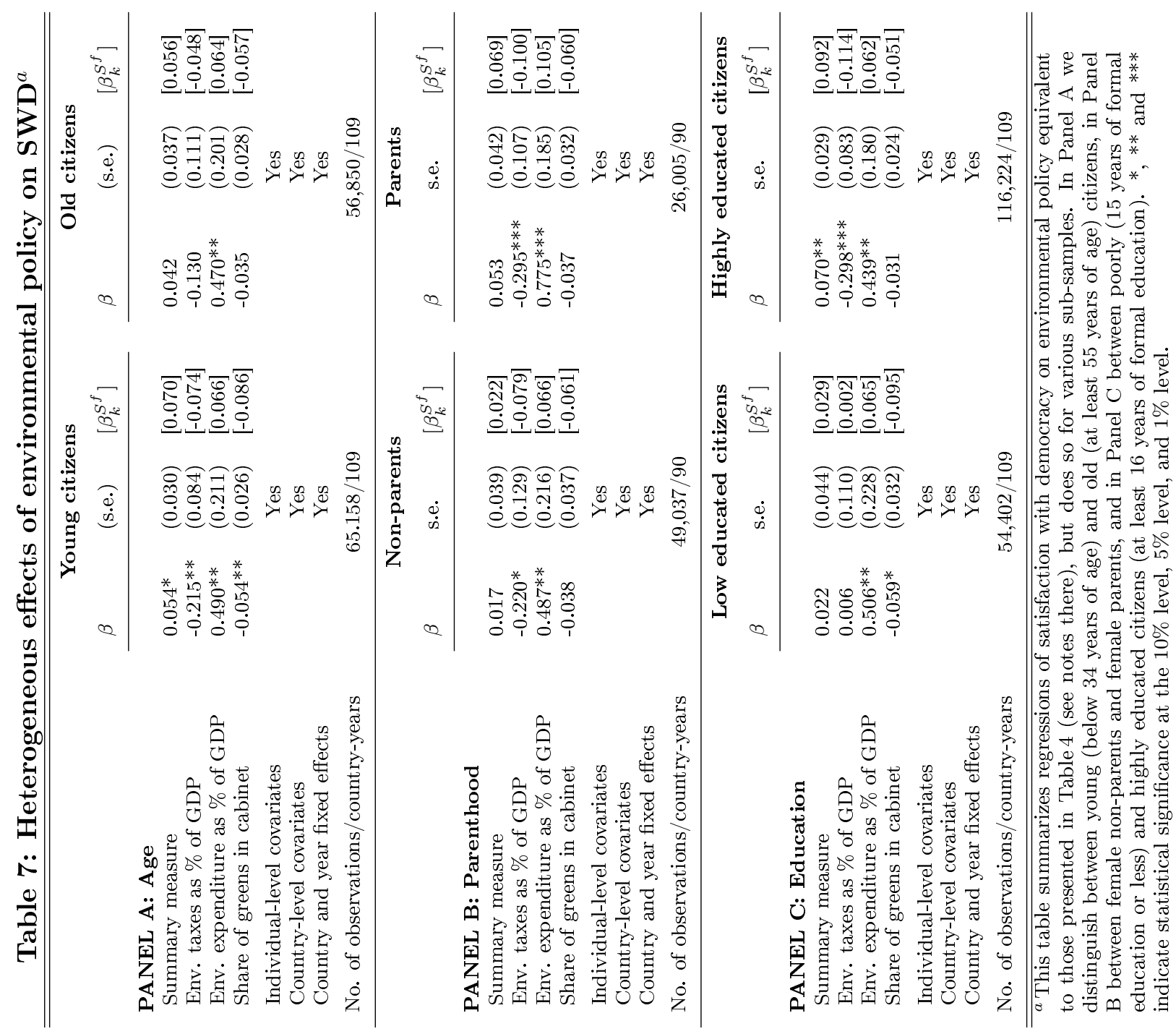




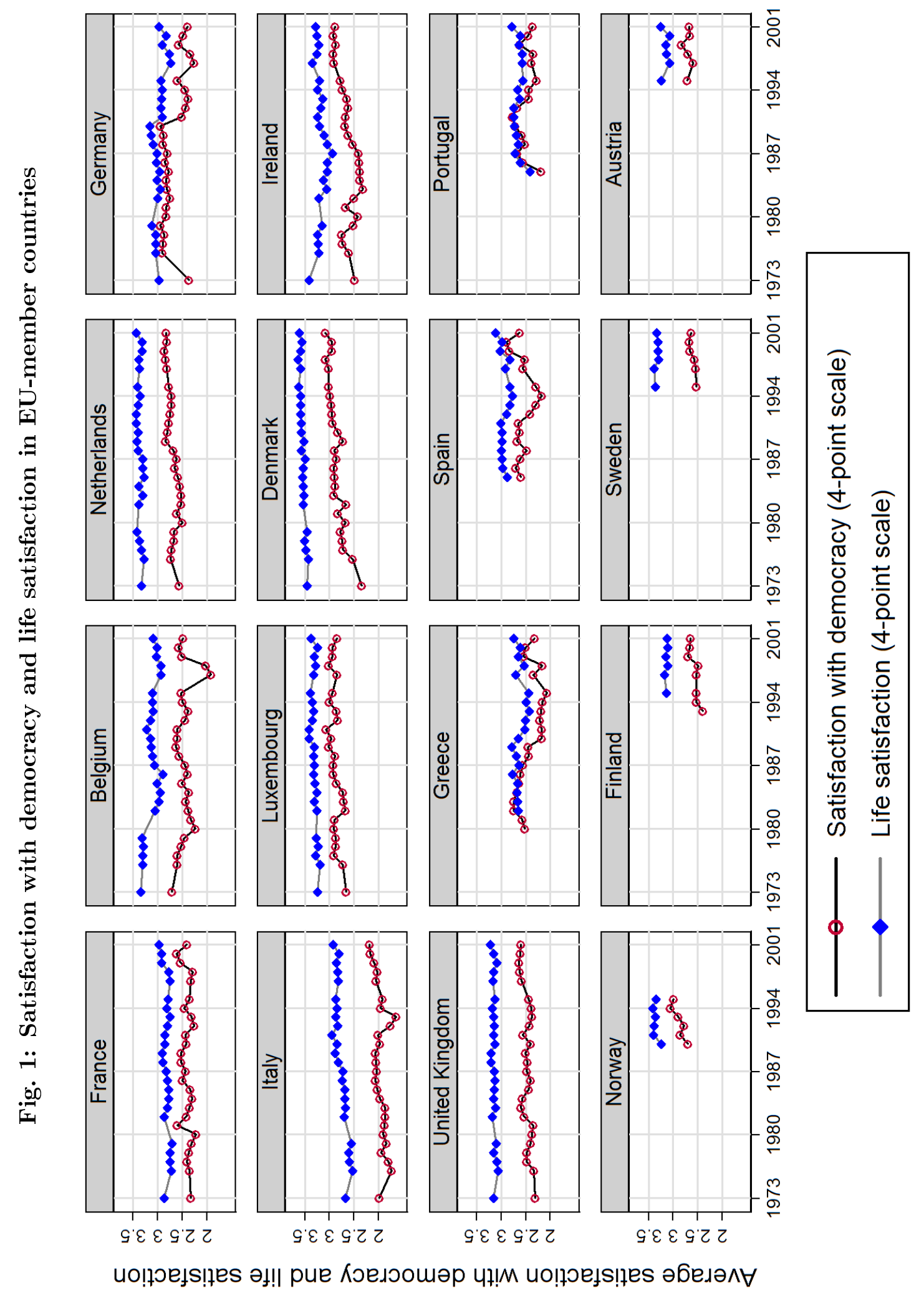




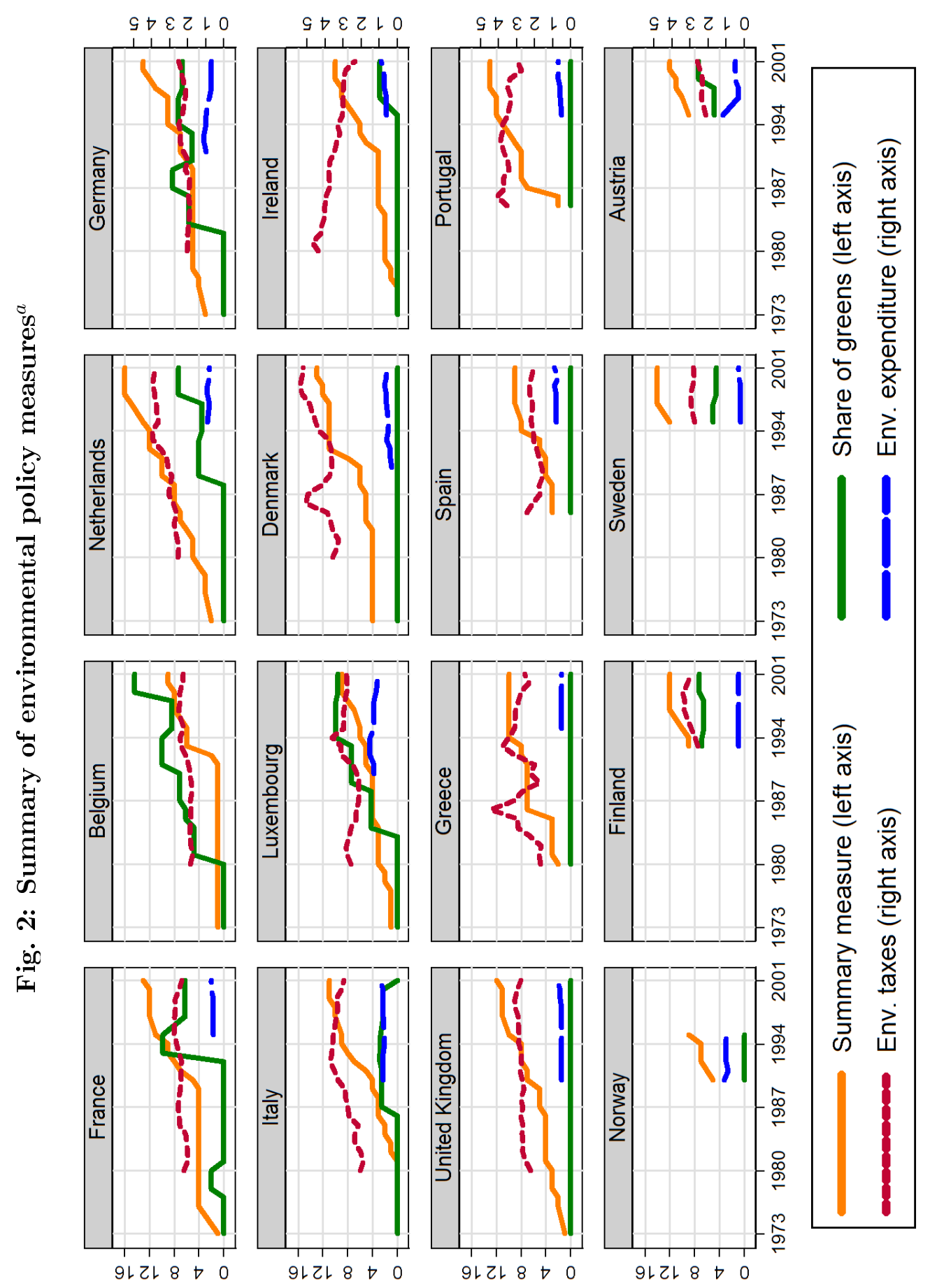

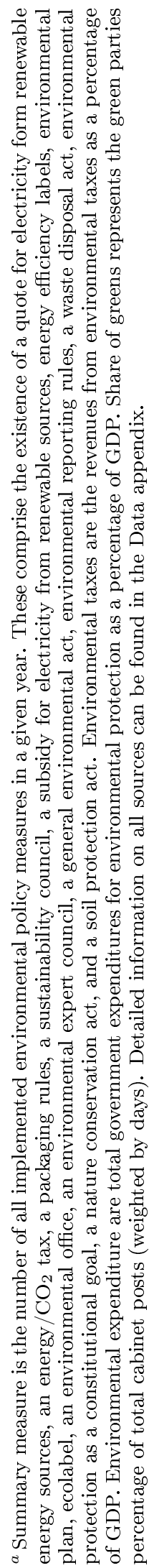




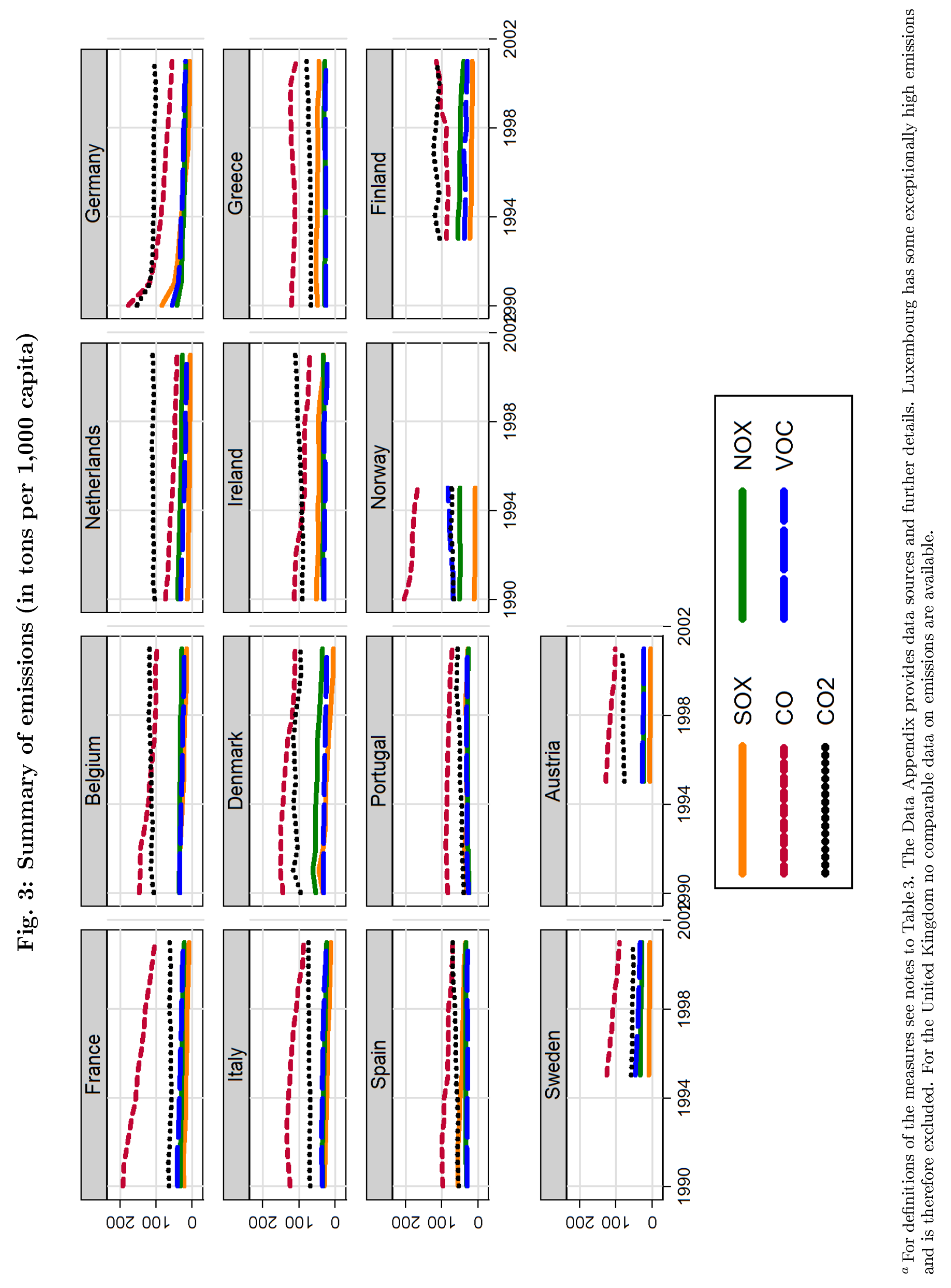




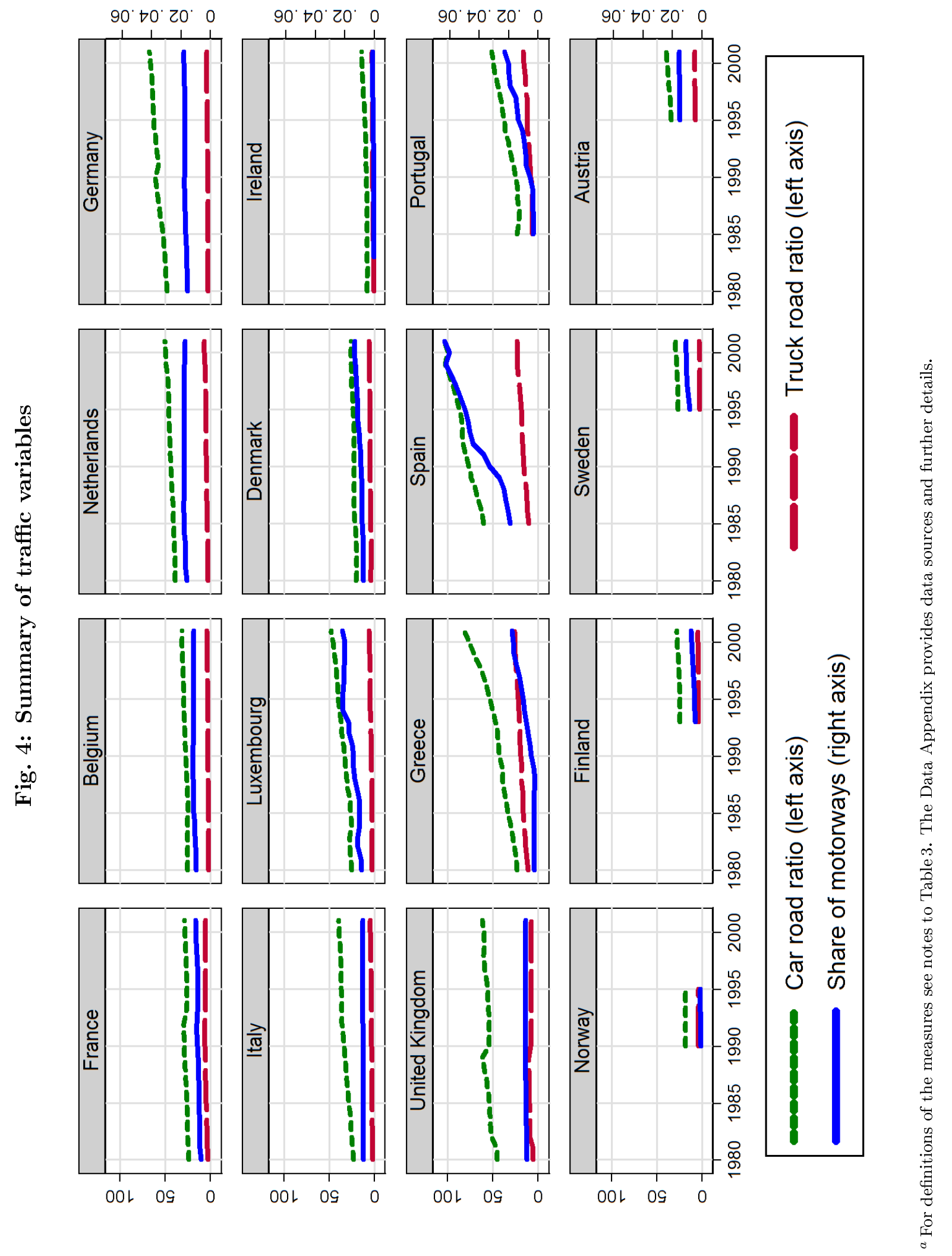

